\title{
INDICADORES PARA REESTRUTURAÇÃO DO CURRÍCULO DE GRADUAÇÃO EM ENFERMAGEM: EXPECTATIVAS DOS PROFISSIONAIS E APRECIAÇĀO DO CURRÍCULO POR EX-ALUNOS
}

\author{
Maria Solange Guarino Tavares* \\ Márcia Caron Ruffino** \\ Branca Maria de Oliveira Santos** \\ Lizete Diniz Ribas Casagrande***
}

TAVARES, M. S. G. et alii. Indicadores para reestruturação do currículo de graauaçāo em enfermagem: expectativas dos profissionais e apreciação do currículo por ex-alunos. Rev.Esc.Enf.USP, São Paulo, 23(2): - , ago. 1989.

Para orientar a reestruturaçāo curricular da Escola de Enfermagem de Ribeirāo Preto - Universidade de São Paulo, foram utilizados como indicadores: 1) levantamento das expectativas dos profissionais de enfermagem quanto à profissão, funçōes, outros membros da equipe e docentes da Escola; 2) apreciação do currículo por esses profissioriais (ex-alunos). Foram consultados 115 enfermeiros dos 5 hospitais gerais de Ribeirão Preto, sendo respondidos 49 questionários $(42,6 \%)$. O questionário entregue pessoalmente ao profissional (juntamente com orientação quanto ao preenchimento e ao prazo de devolução), compunha-se de 9 perguntas abertas. A categorizaçâo das respostas permite afirmar que: a função assistencial é mais enfatizada; as expectativas do indivtduo enquanto aluno se modificam com o exerctcio da profissão; $60 \%$ dos entrevistados consideram adequado o conteúdo das disciplinas de Graduaçâo e 69,4\% consideram dispensáveis as habilitaçōes.

UNITERMOS: Currtculo. Ensino de enfermagem.

\section{INTRODUÇÃO}

Tendo em vista a complexidade dos problemas relacionados ao ensino no país, e a preocupação na formação do profissional de enfermagem, foi que as autoras, envolvidas nos trabalhos de uma Comissăo de Reestruturação Curricular da

* Professor Assistente do Departamento de Enfermagem Materno-Infantil e Saúde Pública da EERPUSP.

** Professores Assistentes Doutores do Departamento de Enfermagem Geral e Especializada da EERP-USP.

*** Professor Assistente Doutor do Departamento de Psicologia e Educação da Faculdade de Filosofia, Ciências e Letras de Ribeirāo Preto-USP. 
Escola de Entermagem de Ribeirāo Preto, USP (EERP), procuraram obter subsídios para o connecimento da realidade em que atuam os egressos desta Escola.

O objetivo îi voter iníormaçōes que ajuäassem no entendimento do processo de formaçāo do eniermeiro, levando em consideraçāo que todo profissional que inicia seu trabalho, tem ainda em mente as disciplinas cursadas em seu período acadêmico e as expectativas quanto à profissāo.

Acreditamos que esses dados possam contribuir pai is ina reforma curricular mais adequada, uma vez que esta se basearia em um diagnóstico da situaŗãa.

Comentando sobre a formação do protisssisalal de enfermagen, cumpic asisinalar alguns conceitos básicos da profissão.

Segundo PONCE DE LEON ${ }^{5}$, ser elıcrmeiro é estar engajado, estar assumindo a ciência e a arte de assistir o ser humano.

Enfermagem em um conceito integral, emitido por Henderson, apud RIBEI$\mathrm{RO}^{6}$, consiste antes de tudo em "ajudar o indivíduo (doente ou sadio) na execução daquelas atividades que contribuem para a manutenção da saúde ou sua recuperaçāo (ou à ier morie serena); atividades que poderia executar sem ajuda de outros, se tivesse lorça e vontade, e os conhecimentos necessários. É também funçāo peculiar de enfermagem preparar os indivíduos para se tornarem independentes desta ajuda, tão rápıdo quanto possível".

A Comissão de Reestruturação Curricular"l definiu enfermagem como "processo de interação que envolve duas pessoas, o enfermeiro e o outro, com o propósito de que este possa atingir melhores niveis de saúde".

A formação do profissional de enfermagem, com as característics acima relacionadas, depende fundamentalmente do currículo cursado por este profissional; daí a necessidade para o plariejamento e avaliação deste currículo, de um conhecimento da realidade em que se insere. Sendo pois, este o pressuposto fundamental das primeiras retiexōes sobre eventuais mudanças do currículo, foi que realizamos esta coleta de material.

O diagnóstico das necessidades, anteriormente realizado pela Comissāo de Reestruturação Curricular, é a primeira área do modelo de planejamento curricular proposto por $\mathrm{SAUL}^{7}$.

Do mesmo modo, outros teóricos de curriculo enfatizam a necessidade de um conhecimento da situaçāo para que se possa preparar os elementos da formaçāo acadêmica. Assim, por exemplo, SAVIANI ${ }^{8}$ afirma: "o homem é um ser situado; possui no entanto a capacidade de intervir na situação, para aceitar, rejeitar ou transformar. Contudo, sua capacidade de intervir na situaçāo está na dependência do grau de consciència que possui desta situaçāo". Além disso, coloca que, "na medida que tomamos consciência das necessidades a serem atendidas, vem-nos a exigência da ação". 
TURRA et alii ${ }^{10}$ colocam que o estabelecimento de uma programação requer levantamento e análise das dimensōes mais significativas da realidade. Antes de formular objetivos e estabelecer estratégia para desenvolvimento de sua açāo junto aos alunos, é essencial que o professor efetue um balanço sistemático das características, condições e problemas da realidade em que vai atuar.

$\mathrm{AEBLI}^{1}$ refere que a teoria de currículo, além da ordem e relaçāo entre conteúdos, examina "as relaçōes das atividades e conteúdo de ensino com as funçōes sociais, econômicas e políticas, que o jovem terá que desempenhar na vida depois de deixar a escola".

Neste sentido, MARTINS 3 afirma que "em qualquer caso de desenvolvimento de currículo, aqueles que o planejam, preferivelmente professores, deveriam iniciar a seleçāo do material a ser ensinado, com uma análise de suદi utilidade".

Segundo uma autoridade em teoria de currículo, $\mathrm{TABA}^{9}$ o que caracteriza um currículo desenvolvido de acordo com o método científico, é o fato de que a tomada de decisōes deriva de um estudo racional dos fatos culturais e sociais presentes na realidade em que se insere a escola.

Em vista deste quadro conceitual sobre as funçōes da enfermagem e com a ênfase encontrada na teoria de currículo, no que se refere ao diagnóstico da situaçāo, nossa preocupaçāo foi levantar informaçōes sobre a realidade local. Assim procurou-se obter dados sobre a opiniāo dos ex-alunos quanto a adequação do conteúdo das disciplinas dos ciclos pré-profissional, profissional e habilitaçōes, à sua prática profissional.

\section{MATERIAL E MÉTODOS}

Com a finalidade acima descrita de obter dados sobre a adequaçāo do currículo da Escola de Enfermagem de Ribeirāo Preto, USP, foram consultados 115 enfermeiros formados por esta escola, de 6 meses a 5 anos, antes de 1980. Tais elementos atuam em diferentes áreas dos cinco hospitais gerais da cidade de Ribeirão Preto, SP.

$O$ instrumento de coleta de dados foi um questionário composto de 9 perguntas, o qual foi entregue pessoalmente pelos pesquisadores aos profissionais, juntamente com a orientação verbal quanto ao preenchimento e o prazo de devoluçāo.

As perguntas do referido questionário acham-se transcritas no item "Resultados", apresentado a seguir, razão pela qual deixamos de anexá-lo.

\section{III - RESULTADOS}

Dos 115 questionários entregues foram devolvidos 49, o que representa $42,6 \%$ do total.

$\mathrm{Na}$ categorização das respostas à primeira questão: " $O$ que significa para 
você ser enfermeiro?", seguimos a definiçāo das funçōes da enfermeira, elaborada pela Comissāo de Reestruturaçāo Curricular, a saber: função assistencial; função integrativa; função administrativa e função educativa.

Foram incluídas, além destas funçóes, as respostas relativas à realizaçāo profissional e da classe (Tabela I), que apareceram em alguns questionários.

TABELA I

DISTRIBUIÇĀO DAS RESPOSTAS SEGUNDO AS FUNÇŌES DEFINIDAS

\begin{tabular}{l|c|c}
\hline \multicolumn{1}{c|}{ FUNÇĀ́O } & FREQ. & $\%$ \\
\hline Assistencial & 15 & 30,6 \\
Integrativa & 10 & 20,4 \\
Administrativa & 10 & 20,4 \\
Educativa & 5 & 10,2 \\
Realizaçăo profissional e da classe & 8 & 16,3 \\
Sem resposta & 1 & 2,1 \\
\hline TOTAL & 49 & 100,0 \\
\hline
\end{tabular}

Quanto à segunda questão: “As expectativas que você tinha 'para vocề como enfermeiro, enquanto aluno da Escola de Enfermagem ou agora depois de estar exercendo a profissāo, sofreram alteraçōes? Quais foram?", os resultados são apresentados na Tabela II.

TABELA II

DISTRIBUIÇĀO DE RESPOSTAS SEGUNDO AS ALTERAÇŌES DAS EXPECTATIVAS DO ENFERMEIRO QUANTO À PROFISSĀO

\begin{tabular}{|c|c|c|c|}
\hline \multicolumn{2}{|c|}{ ALTERAÇŌES DAS EXPECTATIVAS } & FREQ. & $\%$ \\
\hline & $\begin{array}{l}\text { Sim } \\
\text { Nåo } \\
\text { Sem resposta }\end{array}$ & $\begin{array}{r}36 \\
10 \\
3\end{array}$ & $\begin{array}{r}73,4 \\
20,4 \\
6,2\end{array}$ \\
\hline TOTAL & & 49 & 100,0 \\
\hline
\end{tabular}

Dentre as respostas positivas, mencionamos as mais enfatizadas: "preparamo-nos numa especialidade e precisamos trabalhar em outra; nāo estávamos conscientes de não termos os valores necessários para o exercício profissional; enquanto aluno, há estímulos para estudar e pesquisar, depois de formados o horário de trabalho nos tira esse estímulo; a visão dada pela escola é diferente da realidade; delimitar o campo de atuação para desempenhar suas atividades com outros profissionais de saúde; quando aluna, não há tanta responsabilidade e dificuldade com os funcionários; enquanto estudante as funçōes eram: assistência ao ser humano, curar e prevenir, depois descobri administração e integração; escola, tra- 
balho idealista e depois excesso de burocracia e falta de autonomia; enquanto aluno, pensava que houvessem funçōes específicas para enfermeira".

Quanto à questão número três: "Se a educaçāo que recebeu na Escola de Enfermagem deixou lacunas em sua formação profissional, o que você sugere para melhorar esta formação?"', as respostas obtidas estão apresentadas na Tabela III.

TABELA III.

DISTRIBUIÇĀO DE RESPOSTAS, SEGUNDO A EXISTÊNCIA DE LACUNAS NA FORMAÇĀO PROFISSIONAL.

\begin{tabular}{l|c|c}
\hline LACUNAS NA FORMAÇĀO PROFISSIONAL & FREQ. & $\%$ \\
\hline Sim & 44 & 89,8 \\
Não & 2 & 4,0 \\
Sem resposta & 3 & 6,2 \\
\hline TOTAL & 49 & 100,0 \\
\hline
\end{tabular}

Além das respostas acima foram solicitadas aos respondentes, sugestōes que transcremos a seguir: "a escola deve oferecer: mais oportunidade e liberdade de ação aos alunos; mais supervisão direta e ensino; mudanças no currículo; disciplinas de integraçāo com as relaçōes humanas; mais estágios práticos e menos teoria; os alunos deveriam conhecer outra realidade hospitalar; aumentar a carga horária dos estágios".

A quarta questāo, dividida em dois itens "Quais as suas expectativas quanto: a) aos enfermeiros (de cabeceira); b) aos doentes da Escola de Enfermagem", os resultados apresentam-se respectivamente nas tabelas IV e V.

TABELA IV

DISTRIBUIÇĀO DAS RESPOSTAS, SEGUNDO AS EXPECTATIVAS DO PROFISSIONAL QUANTO AOS ENFERMEIROS (DE CABECEIRA)

\begin{tabular}{|c|c|c|}
\hline EXPECTATIVAS COM RELAÇĀO AO ENFERMEIRO & FREQ. & $\%$ \\
\hline $\begin{array}{l}\text { Dar cuidado mais direto e integral ao paciente } \\
\text { Ter maior segurança, liberdade e autonomia no seu } \\
\text { campo de ação } \\
\text { Assumir mais o paciente, deixando de lado as } \\
\text { questōes burocráticas } \\
\text { Coordenar, supervisionar e colaborar na elaboraçāo } \\
\text { do plano assistencial } \\
\text { Sem res,iosta }\end{array}$ & $\begin{array}{l}26 \\
8 \\
7 \\
5 \\
3\end{array}$ & $\begin{array}{r}53,1 \\
16,3 \\
14,3 \\
10,2 \\
6,1\end{array}$ \\
\hline TOTAL & 49 & 100,0 \\
\hline
\end{tabular}


TABELA $V$

DISTRIBUIÇÃO DAS RESPOSTAS, SEGUNDO AS EXPECTATIVAS DO

PROFISSIONAL QUANTO AOS DOCENTES

\begin{tabular}{l|r|r}
\hline EXPECTATIVAS DO PROFISSIONAL QUANTO AOS DOCENTES & Freq. & \multicolumn{1}{c}{$\%$} \\
\hline Responsáveis pelo aprendizado, integrando-se à realidade dos alunos e profissionais & 28 & 57,1 \\
Maior supervisăo e apoio em campo de estágio & 7 & 14,2 \\
Divulgaçāo de novos trabalhos em enfermagem & 4 & 8,2 \\
Colaborar nas diretrizes do serviço de enfermagem & 3 & 6,2 \\
Transmitir conhecimentos teóricos e práticos atualizados & 2 & 4,1 \\
Sem resposta & 5 & 10,2 \\
\hline TOTAL & 49 & 100,0 \\
\hline
\end{tabular}

Com respeito a questão número cincu "A seguir você encontrará uma relação de disciplinas pertencentes ao Currículo da Escola de Enfermagem de Ribeirão Preto sobre as quais você deverá mencionar, baseado na sua experiência atual o que julga:

- que ficou claramente faltando;

- que ficou supérfluo;

- se o conteúdo foi inadequado;

- se o conteúdo foi adequado",

obtivemos os seguintes resultados, apresentados na Tabela VI, quanto as disciplinas do ciclo pré-profissional.

TABELA VI

DISTRIBUIÇĀO DAS RESPOSTAS DOS PROFISSIONAIS, RELACIONADAS AO CONTEÚDO DAS DISCIPLINAS DO CICLO PRE-PROFISSIONAL DO CURRICULO DA E.E.R.P.

\begin{tabular}{|c|c|c|c|}
\hline Disciplinas & $\begin{array}{l}\text { Conteádo } \\
\text { adequado }\end{array}$ & $\begin{array}{l}\text { Conteúdo } \\
\text { inadequado }\end{array}$ & $\begin{array}{c}\text { Sem } \\
\text { resposta }\end{array}$ \\
\hline $\begin{array}{l}\text { Psicologia Geral } \\
\text { Sociologia } \\
\text { Didática Aplicada à Enfermagem } \\
\text { Evolução da Enfermagem } \\
\text { Bioquímica } \\
\text { Genética } \\
\text { Morfologia I (Biologia celular, } \\
\text { Histologia e Embriologia), } \\
\text { Microbiologia } \\
\text { Educaçāo Fisica } \\
\text { Introdução à Estatística Aplicada } \\
\text { a Saúde } \\
\text { Introdução à Saúde Pública (Saư- } \\
\text { de Comunitária e Saneamento). } \\
\text { Nutrição } \\
\text { Fisiologia } \\
\text { Morfologia Il (Anatomia) } \\
\text { Patologia } \\
\text { Parasitologia }\end{array}$ & $\begin{array}{l}41 \\
23 \\
25 \\
28 \\
28 \\
30 \\
38 \\
45 \\
20 \\
\\
35 \\
\\
37 \\
20 \\
36 \\
30 \\
30 \\
48\end{array}$ & $\begin{array}{r}4 \\
12 \\
12 \\
6 \\
12 \\
12 \\
6 \\
2 \\
6 \\
4 \\
\\
5 \\
18 \\
6 \\
9 \\
6 \\
1\end{array}$ & $\begin{array}{r}4 \\
14 \\
12 \\
15 \\
9 \\
7 \\
\\
5 \\
2 \\
23 \\
\\
10 \\
\\
7 \\
11 \\
7 \\
10 \\
13 \\
0\end{array}$ \\
\hline \multirow{2}{*}{ TOTAL } & $\mathrm{n}^{\mathrm{e}}$ & $\mathrm{n}^{\circ}$ & $\mathrm{n}^{\circ}$ \\
\hline & 514 & 15,4 & 149 \\
\hline
\end{tabular}


Na tabela VII, apresentamos as opiniões dos profissionais sobre a adequabilidade das disciplinas do ciclo profissional.

TABELA VII

DISTRIBUIÇĀO DAS RESPOSTAS DOS PROFISSIONAIS, QUANTO AO CONTEÚDO DAS DISCIPLINAS DO CICLO PROFISSIONAL DO CURRICULO DA E.E.R.P.

\begin{tabular}{|c|c|c|c|}
\hline Disciplinas & $\begin{array}{l}\text { Contefido } \\
\text { adequado }\end{array}$ & $\begin{array}{c}\text { Contefido } \\
\text { inadequado }\end{array}$ & $\begin{array}{c}\text { Sem } \\
\text { resposta }\end{array}$ \\
\hline $\begin{array}{l}\text { Fundamentos de Enfermagem } \\
\text { Epidemiologia } \\
\text { Estudo das Relaçóes Enfermeiro- } \\
\text { Paciente I } \\
\text { Farmacologia } \\
\text { Enfermagem Médica I } \\
\text { Enfermagem Cirúrgica I } \\
\text { Dietoterapia } \\
\text { Enfermagem de Molestias } \\
\text { Transmissfveis } \\
\text { Estudo das Relaçóes Enfer- } \\
\text { meiro-Paciente II } \\
\text { Enfermagem Obstétrica e Gine- } \\
\text { cológica I } \\
\text { Pediatria } \\
\text { Estudo das Relaçoes Enfer- } \\
\text { meiro-Paciente III } \\
\text { Exercf́io da Enfermagem } \\
\text { Estudo de Problemas Brasileiros I } \\
\text { Administração } \\
\text { Enfermagem de Sađde Pública I } \\
\text { Enfermagem Psiquiátrica } \\
\text { Estudo de Problemas Brasileiros II }\end{array}$ & $\begin{array}{c}33 \\
29 \\
\\
40 \\
30 \\
36 \\
30 \\
19 \\
44 \\
39 \\
38 \\
40 \\
39 \\
24 \\
21 \\
35 \\
37 \\
41 \\
25\end{array}$ & $\begin{array}{r}2 \\
8 \\
4 \\
9 \\
5 \\
7 \\
17 \\
2 \\
2 \\
4 \\
\\
5 \\
1 \\
3 \\
9 \\
17 \\
7 \\
3 \\
4 \\
12\end{array}$ & $\begin{array}{r}14 \\
12 \\
5 \\
5 \\
10 \\
8 \\
12 \\
13 \\
3 \\
3 \\
6 \\
\\
6 \\
8 \\
\\
7 \\
16 \\
11 \\
7 \\
9 \\
4 \\
12\end{array}$ \\
\hline \multirow[t]{2}{*}{ TOTAL } & $\mathrm{n}^{\circ}$ & $\mathrm{n}^{\circ}$ & $\mathrm{n}^{\circ}$ \\
\hline & 600 & 119 & 163 \\
\hline
\end{tabular}

Nas tabelas VIII, IX e X, apresentamos as respostas dos profissionais sobre as habilitaçöes oferecidas pela Escola de Enfermagem de Ribeirão Preto, USP, na época de sua formaçāo.

TABELA VIII

DISTRIBUIÇĀO DAS RESPOSTAS QUANTO AO CONTEÚDO DAS DISCIPLINAS DA HABILIT AÇĀO EM ENFERMAGEM MÉDICO-CIRÚRGICA

\begin{tabular}{|c|c|c|c|c|}
\hline $\begin{array}{c}\text { Disciplinas da Habilitaçāo } \\
\text { Médico-Círúrgica }\end{array}$ & $\begin{array}{l}\text { Contefido } \\
\text { adequado }\end{array}$ & $\begin{array}{l}\text { Conteado } \\
\text { inadequado }\end{array}$ & & sta \\
\hline $\begin{array}{l}\text { Enfermagem Cirúrgica II } \\
\text { Administraçăo de Serviço Hospitalar } \\
\text { Administração do Centro Cirứrgico } \\
\text { Enfermagem Médica II } \\
\text { Enfermagem Psiquiátrica Preventiva }\end{array}$ & $\begin{array}{l}12 \\
16 \\
11 \\
16 \\
21\end{array}$ & $\begin{array}{l}3 \\
2 \\
3 \\
2 \\
2\end{array}$ & & $\begin{array}{l}4 \\
1 \\
5 \\
1 \\
6\end{array}$ \\
\hline \multirow{2}{*}{ TOTAL } & $\mathbf{n}^{\mathbf{0}} \quad \%$ & $n=$ & $n^{\circ}$ & $\%$ \\
\hline & $76 \quad 60,8$ & 9,6 & 34 & 23,6 \\
\hline
\end{tabular}


TABELA IX

DISTRIBUIÇÃO DAS RESPOSTAS QUANTO AO CONTEÚDO DAS DISCIPLINAS DA HABILITAÇÃO EM ENFERMAGEM DE SAÚDE PÚBLICA

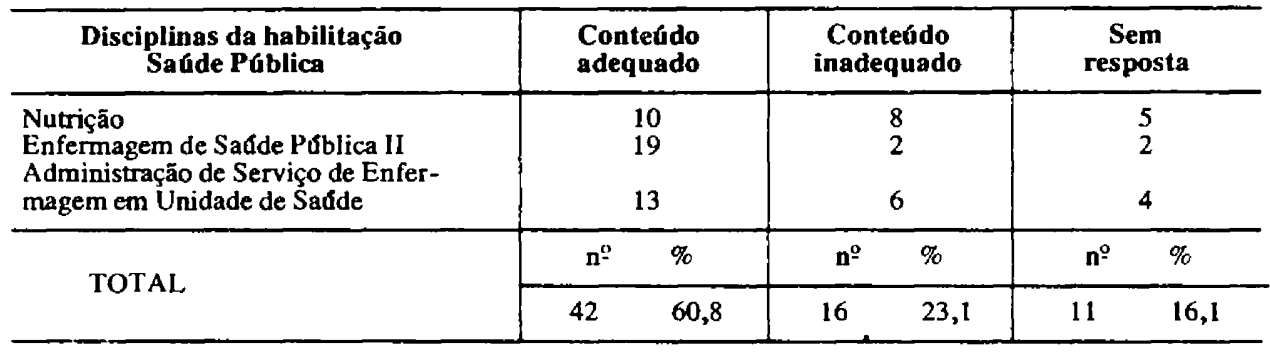

TABELA X

DISTRIBUIÇĀO DE RESPOSTAS QUANTO AO CONTEÚDO DAS DISCIPLINAS DA HABILITAÇÃO EM ENFERMAGEM OBSTÉTRICA E GINECOLÓGICA

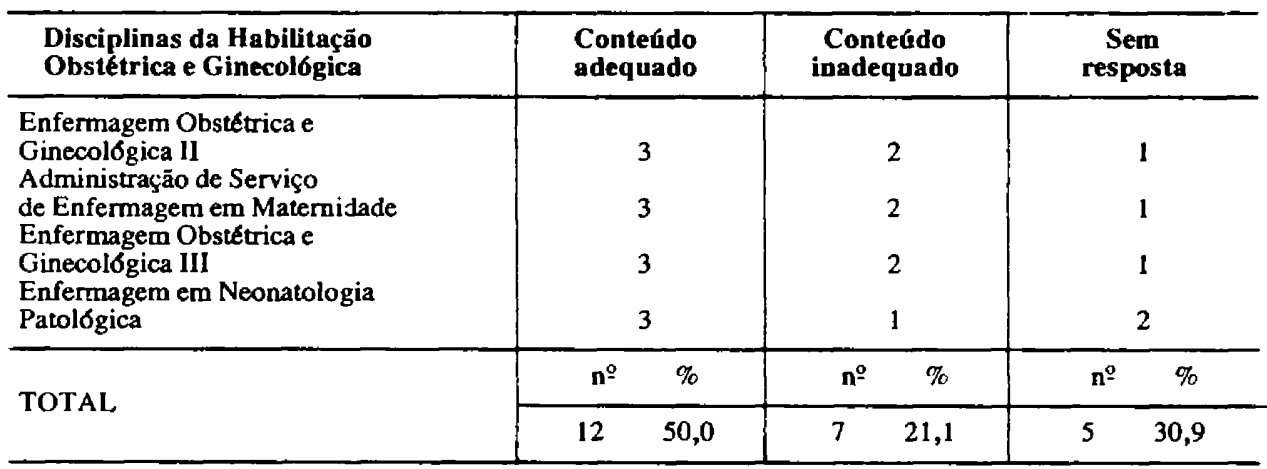

Quanto à sexta pergunta “Que área de habilitação cursou?", obtivemos os resultados apresentados na Tabela XI.

TABELA XI

DISTRIBUIÇĀO DE PROFISSIONAIS, SEGUNDO A ÁREA DE HABILITAÇÃO CURSADA

\begin{tabular}{l|c|c}
\hline \multicolumn{1}{c|}{ Habilitaçäo Cursada } & Freq. & $\%$ \\
\hline Enfermagem Saúde Pública & 23 & 49,9 \\
Enfermagem Obstétrica e Ginecologica & 6 & 12,2 \\
Enfermagem Médico-Cinurgica & 19 & 38,8 \\
Sem resposta & 1 & 2,1 \\
\hline TOTAL & 49 & 100,0 \\
\hline
\end{tabular}

Os resultados obtidos na sétima pergunta: “"̈n? qual área trabalha agora?”, estãu apresentados na tabela XII. 
TABELA XII

DISTRIBUIÇĀO DA ÁREA DE ATUAÇÃO DO PROFISSIONAL

\begin{tabular}{l|c|c}
\multicolumn{1}{c|}{ Area de atuaçio } & Freq. & \% \\
\hline Cirúrgica & 20 & 40,8 \\
MEdica & 4 & 8,1 \\
Ginecologia e Obstetricia & 6 & 12,2 \\
Ensino & 9 & 18,3 \\
Hospital Particular Geral & 1 & 2,1 \\
Saúde Pública & 1 & 2,1 \\
Pediatria & 4 & 8,1 \\
Psiquiatria & 2 & 4,1 \\
Ambulatório Especializado & 1 & 2,1 \\
Sem resposta & 1 & 2,1 \\
\hline TOTAL & 49 & 100,0 \\
\hline
\end{tabular}

Quanto a oitava questão, "Acredita que a habilitação (4" ano) ajudou na sua formaçâo?", obtivemos as respostas apresentadas na Tabela XIII.

\section{TABELA XIII}

DISTRIBUIÇĀO DE RESPOSTAS DOS PROFISSIONAIS SOBRE A AJUDA DA HABILITAÇĀO NA SUA FORMAÇĀO

\begin{tabular}{l|c|c}
\hline \multicolumn{1}{c|}{ Ajudou } & Freq. & $\%$ \\
\hline Sim & 35 & 71,4 \\
Nio & 13 & 26,5 \\
Sem resposta & 1 & 2,1 \\
\hline TOTAL & 49 & 100,0 \\
\hline
\end{tabular}

Os resultados da nona questāo "Será indispenschvel continuar havendo habilitação no Curso de Enfermagem? Qual a sua opinião?", estäo contidos na Ta-bela XIV.

TABELA XIV

DISTRIBUIÇĀO DAS RESPOSTAS DOS PROFISSIONAIS QUANTO A HABILITAÇĀO SER INDISPENSÁVEL PARA SUA FORMAÇĀO

\begin{tabular}{l|c|c}
\hline \multicolumn{1}{c|}{ Habilitacio e Indispensived } & Freq. & \% \\
\hline Sim & 11 & 22,4 \\
Nao & 37 & 75,5 \\
Sem resposta & 1 & 2,1 \\
\hline TOTAL & 49 & 100,0 \\
\hline
\end{tabular}


Os argumentos a favor da permanência da habilitação no Currículo foram: "vai auxiliar na formação profissional; trabalho na área em que fui habilitado; habilitação ajuda a solidificar o que aprendemos nos anos anteriores; o quarto ano é utilizado para desenvolver disciplinas profissionalizantes com mais profundidade; com a habilitaçāo, o profissional é inseguro, imagine sem ela; com a habilitação praticamos um pouco mais o que aprendemos durante outros anos do curso; deve ser proporcionado ao aluno, um ano de experiência no atendimento intensivo".

Os argumentos contra a permanência da habilitação no Currículo foram: "devemos nos aprofundar mais em todas as áreas; maior carga horária nas diferentes disciplinas e com maior visāo do todo; porque não se sabe onde iremos desempenhar nossas funçōes; com perfodo mais longo para estagiar nas áreas oferecidas no segundo ano do curso; deve-se aumentar o período das disciplinas dos outros semestres; em lugar da habilitação, o curso deve permitir a passagem por diferentes clínicas, dando uma noção de enfermagem como um todo; só vamos aprender mesmo, quando exercemos a profissāo; a enfermagem tem um campo de trabalho restrito e a realidade brasileira necessita de generalistas e não especialistas; deve-se estender mais as disciplinas do terceiro ano, ocupando o período seguinte, isto é, o quarto ano; o curso deveria ser mais integrado sem divisões e/ou especialidades; a escola deve preocupar-se mais com o aprimoramento profissional, não na forma de habilitação".

\section{IV - DISCUSSĀO}

Os resultados apresentados na Tabela I, permitem afirmar que a função assistencial foi a mais enfatizada, dado este corroborado pelo trabalho apresentado no ENCONTRO SOBRE CURRÍCULO².

Refere o grupo ser esta a área que dá mais satisfaçāo às enfermeiras, mesmo dispendendo elas mais tempo com as atividades administrativas. Além đisso, esta função assistencial volta a aparecer como uma preocupaçãc básica dos profissionais, ao apresentarem suas expectativas com relação ao enfermeiro de cabeceira. Com efeito na tabela IV, pode-se perceber que cerca de $67,4 \%$ das respostas reafirmam dever este enfermeiro prestar maior assistência ao paciente.

Entretanto, o estudo realizado por MENDES et alii ${ }^{4}$, em um hospital escola, constatou que cerca de $70 \%$ da assistência de enfermagem é realizada por atendentes.

Chama-nos a atenção ainda, o fato de que a função educativa ocupou o quarto lugar nesta tabela, ou seja, apenas $10,2 \%$ das resposas enfatizou o papel educativo da enfermeiro.

Segundo resultados apresentados na Tabela II, para 73,4\% das enfermeiras, a vivência e o desempenho atual da profissāo não correspondem às suas expectativas, enquanto estudanies. Através das respostas mencionadas, podemos observar que o conteúdo das justificativas apresentam razōes para essa divergência. 
Por exemplo: "A visăo dada pela escola é diferente da realidade". Nisto ha muita razão sob vários pontos de vista. Primeiro, os campos de extagio predominantes ma escola são voltados para assistencia secundária e tercifria a sarde (hospitais com pacientes internados). $O$ campo ambulatorial e de comunidade 6 bem menos explorado. Através da utilizaç̧̃o destes últimos, a eacola poderia moctrar mais a realidade do estado de saude da populaçâ. Segundo, que os campos de cetígio oferecidos predominantemente na escola, possuem recursos financeiros, materiais e humanos que så melhores em qualidade e quantidade, se comparados com a maioria dos outros hospitais do pars - portanto nfo comespondem à realidade.

Em terceiro lugar, na atuagåo do aluno em campo, os docentes enfatizam predominantemente a interaçấ com o paciente e os aspectos psico-sociais, ou seja, o paciente como um todo - e isto, embora constitua filosofia de trabalho muito positiva, nåo prepara o aluno para o mercado de trabalho, no qual esta 6 uma tarefa relegada a segundo plano. Portanto, $C$ mais um fator que leva a contrastar a escola com a realidade.

Quanto à existência de lacunas na formaçăo profissional 6 evidente, pela Tabela III, que os ex-alunos as percebem acentuadamente $(89,8 \%)$.

É sabido que todo curso de graduaçăo tem deixado lacunas na formação do profissional - porém, essa alta porcentagem constitui motivo sćrio para reflexão dos docentes interessados na adequaçăo dos cursos. Consideramos as sugestôes apresentadas pelos profissionais como válidas e viáveis, na medida em que refletem problemas sentidos pelos proprios docentes, como já referimos quanto à Tabela II.

Pela Tabela IV, constata-se que a maior expectativa do profissional quanto ao enfermeiro de cabeceira é "dar cuidado mais direto e integral ao paciente" $(53,1 \%)$. Im segundo lugar, aparece o desejo de liberdade e autonomia no seu campo de açāo (16,3\%); em terceiro lugar, "assumir mais o paciente, deixando de lado as questōes burocráticas" (14,3\%), é resposta vinculada à primeira, pois também expressa a expectativa de dar cuidado direto ao paciente. Em quarto lugar, "coordenar, supervisionar e colaborar na elaboração do plano assistencial" $(10,2 \%)$, representa igualmente (como a primeira e terceira respostas) afinidade com o cuidado de enfermagem, pois nenhuma assistência de enfermagem é eficiente sem uma colaboração do plano assistencial.

Deste modo, percebe-se que a espectativa principal dos egressos da escola de enfermagem quanto ao seu papel é fundamentalmente ligada à função assistencial.

Quanto à expectativa do profissional com relaçāo aos docentes, expressa na tabela V, as respostas obtidas sugerem: mais integração à realidade dos alunos e dos enfermeiros $(57,1 \%)$; mais supervisāo e apoio em campo de estágio $(14,2 \%)$; e divulgaçāo de trabalhos $(8,2 \%)$. 
Chama-nos a atenção o fato de que sugerem menos a colaboração nas diretrizes do serviço $(6,2 \%)$, e a simples transmissão de conhecimentos teóricos e práticos $(4,1 \%)$.

Extremamente importante, a nosso ver, é a ênfase na atribuição da responsabilidade pelo aprendizado ao professor $(57,1 \%)$. Ao que parece, o aluno năo se percebe como "sujeito do processo ensino-aprendizagem", ativamente envolvido na situaçāo preparada pelo professor para favorecer essa aprendizagem. Ao contrário, abdica da responsabilidade pessoal por sua própria formação, delegando-a ao professor, demonstrando uma dependência em relação ao mestre.

Quanto à adequação do conteúdo das disciplinas do ciclo pré-profissional, observamos pela Tabela VI que $65,5 \%$ dos ex-alunos consideraram o total dos conteúdos como adequado sendo que $15,4 \%$ o consideraram inadequado.

Quanto à adequação do conteúdo das disciplinas do ciclo profissional, $68,0 \%$ dos enfermeiros o consideraram adequado, demonstrando que de um modo geral, a maioria se considerava suficientemente preparada para o exercício da profissão. Isso entra em contradiçāo com as afirmaçōes anteriores, sobretudo, as contidas na Tabela III que constatam lacunas na formação profissioal $(89,8 \%)$. Que fatores explicariam essa contradição?

Em relação à Habilitaçāo em Enfermagem Médico-Cirúrgica e Enfermagem em Saúde Pública, a porcentagem de profissionais que considerou o conteúdo adequado foi $60,8 \%$, segundo tabelas VIII e IX. Já em relação à Habilitação em Enfermagem Ginecológica e Obstétrica, a porcentagem de respostas considerando o conteúdo adequado foi de $50 \%$ (tabela $\mathrm{X}$ ).

Tais dados são corroborados pelos da tabela XIII, em que 71,4\% dos profissionais considerou que a habilitação ajudou na sua formaçāo.

Comparando-se os resultados apresentados nas tabelas XI e XII, observa-se que dos 23 habilitados em Saúde Pública, somente 1(um) está trabalhando na referida área, ao passo que os seis profissionais que cursaram Habilitação em Ginecologia e Obstetrícia, estão exercendo a profissão na área cursada.

Constata-se uma disparidade no número de profissionais que cursaram Habilitaçāo Médico-Cirúrgica (19) e no número de profissionais atuando nesta área (29) - Profissionais formarns em outras habilitaçōes estão, portanto, atuando nesta área (40\%).

Na tabela XIII como vimos, $71,4 \%$ dos profissionais admitiram ter a habilitação contribuído para sua formação. Isto configura uma contradiçāo com as respostas da tabela XIV, onde observa-se que $75,5 \%$ dos profissionais julgam que a habilitação é dispensável no currículo de enfermagem, enquanto que apenas $22,4 \%$ a consideram indispensável.

Surgiram argumentos pró e contra a permanência das Habilitaçōes no currí- 
culo; dentre eles destacamos a idéia de que a mesma permite o aprofundamento e a solidificação de conhecimentos anteriormente adquiridos. Ao contrário, aparece também a idéia de que a realidade brasileira necessita de enfermeiros generalistas, e não de especialistas.

\section{V - CONSIDERAÇŌES FINAIS}

1. Foi possível através do levantamento de opiniões de ex-alunos, extrair dados a respeito da realidade em que atuam os egressos da Escola de Enfermagem de Ribeirão Preto, USP.

2. As informações obtidas permitiram a elaboraçāo de alguns indicadores para a reestruturação do currículo da referida escola, a saber:

a) expectativa do profíssional quanto a sua própria funçāo;

b) expectativa dos ex-alunos com relação aos docentes da Escola de Enfermagem de Ribeirão Preto, USP;

c) adequação do conteúdo das disciplinas dos ciclos pré-profissional e profissional.

Em relaçāo ao indicador "função do profissonal de enfermagem" constatouse a preferência pela função assistencial, do que se depreende a necessidade de adaptar o currículo de modo a capacitar o aluno para o exercício desta função.

Quanto ao indicador "expectativa dos ex-alunos com relação aos docentes", concluimos que há acentuada dependência do aluno ao docente e o desejo de que, ao assumir a responsabilidade pela aprendizagem, o professor se integre à realidade dos alunos e profissionais.

Para o indicador "adequação do conteúdo das disciplinas dos ciclos pré-profissional e profissional" concluimos que, embora o profissional perceba lacunas na sua formaçāo, não as atribui ao currículo acadêmico propriamente dito. Essas observaçōes referidas parecem sugerir que essas lacunas se localizam nos campos de estágio, nas oportunidades de aliar teoria e prática e de aplicar informaçōes teóricas às situaçōes reais.

TAVARES, M. S. G. et alii. Indicators for changing nursing graduation curriculum: professional's expectations and graduates' evalutation of curriculum. Rev. Esc. Enf. USP, São Paulo, 23(2): -, Aug. 1989.

Two kinds of evidence were used to guide curriculum changes in the Nursing School of Ribeirāo Preto (University of Sāo Paulo): I) a survey of nurses' expectations on their profession, their functions, the other members of the team and on the Nursing School teachers; 2) yraduates' (ex-students) curriculum evaluation. 
We inquired 115 nurses working in 5 general hospitals of Ribeirão Preto, and had a return of 49 questionaries $(42,6 \%)$. This questionary was delivered by the authors personally to the nurses, along with guidances on answering and date for return, and had 9 opened questions.

The classification of answers makes possible to assert: the assistance function is the most emphasized by nurses; the student's expectations change during the professional practice; $60 \%$ of the informants considered the content of the curriculum disciplines adequate; $69,4 \%$ considered the habilitations dispensable.

UNITERMS: Curriculum. Education, nursing.

\section{REFERENNCIAS BIBLIOGRÁFICAS}

1. AEBLI, H. A teoria do currfculo e o problema dos objetivos da aprendizagem. In:-_. Prática de ensino: formas fundamentais de ensino elementar, médio e superior. 11.ed. São Paulo, EDUSP, 1979. cap.12, p.261-82.

2. ENCONTRO SOBRE CURRICULO, 2., S5o Paulo. Resultados de uma investigação sobre a profissão. São Paulo, Escola de Enfermagem da USP, 1983. 3p (mimeografado).

3. MARTINS, J. Modelo de planejamento curricular. In: GARCIA, W. E. Educação brasileira contemporánea: organizaçāo e funcionamento. Rio de Janeiro, McGraw Hill, 1978. p.43-68.

4. MENDES, 1. A. C. et alii. Análise crftica do processo decisorio em enfermagem. Rev.Bras.Enf., Brasflia, 30(4):404-11, out./dez. 1977.

5. PONCE DE LEON, S. A. Objetivos e valores da profissāo. Enf.Novas Dimens., Săo Paulo, I(1):29-36, mar./abr. 1975.

6. RIBEIRO, C. M. A gestăo administrativa da enfermagem integral nos serviços de saúde. Rev.Bras.Enf., Rio de Janeiro, 24(1/2):70-100, jan./mar. 1971.

7. SAUL, A. M. Modelo de pesquisas em ação aplicado ao treinamento de professores. Sảo Paulo, 1971. (Dissertaçăo de mestrado - Pontifícia Universidade Católica).

8. SAVIANI, D. Subsídios para fundamentaçăo do currículo da PUC-SP. In:-_ـ_. Educaçáo: do senso comum à consciência filos ́fica. São Paulo, Cortez, 1980. p.63-9.

9. TABA, H. Introduccion al planeamiento del curriculo. In:-_. Elaboracion del currícu10. 2.ed. Buenos Aires, Troquel, 1976. cap.1, p.13-32.

10. TURRA, C. M. G. et alii. Fases do planejamento de ensino. In:-_. Planejamento de ensino e avaliaçäo. 4.ed. Porto Alegre, PUC-EMA, 1985. cap.2, p.23-55.

11. UNIVERSIDADE DE SĀO PAULO. Escola de Enfermagem de Ribeirão Preto. Comissăo de Reestruturação Curricular. Estudo da reformulaçāo Curicular do Curso de Graduaçāo da Escola de Enfermagem de Ribeirão Preto. Rev.Esc.Enf.USP, São Paulo, 16(2):137-46, ago. 1982. 